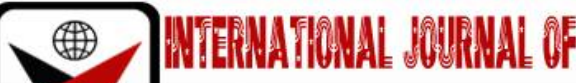

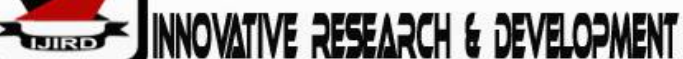

ISSN 2278 - 0211 (Online)

\section{Exploring the Scope of Intervention Strategies Employed by Tertiary Institutions in the Implementation of Inclusive Education in Zimbabwe}

\author{
Albetina Kunodziya \\ Lecturer, Department of Theory of Education, Masvingo Teachers College, Zimbabwe \\ Zadzisai Machingambi \\ Lecturer, Department of Psychology, Zimbabwe Open University, Zimbabwe
}

\begin{abstract}
:
The concept of inclusive education has attracted the active attention of many scholars, academics and even ordinary people in Zimbabwe and globally. This study sets itself to review landmarks in the evolution of inclusive educationin Zimbabwe in response to developments in Zimbabwe and on the international arena. As the discourse unfolds intervention strategies adopted by tertiary institutions in implementing inclusive education are highlighted. In order to get a deeper insight into the extent to which inclusive education is being implemented in Zimbabwe, the researchers engaged a case study of Masvingo Teachers' College. The college is one of the many tertiary institutions in the country. Pursuant to this objective, it was deemed important to assess the college's thrust in articulating inclusive education on critical focal areas such as: accessibility of library and office rooms; sports; compatibility of lecture and dining rooms; the service environment and teaching practice support services. The discussion extends to cover the benefits of inclusive education. The major findings of this study were that: (i) The College had crafted excellent policy documents in favour of inclusive education. (ii) The political will to implement inclusive education though evident but was not matched with the objective reality that obtained on the ground. (iii) The college was seriously lagging behind in terms of upgrading infrastructure and technical services to meet the modern requirements for effective implementation of inclusive education. The basic conclusion was that the massive resources required to fully implement inclusivity were grossly inadequate both from the local college level and central government perspective. On the basis of observed findings and conclusions the paper winds up by promulgating a number of recommendations envisioned to improve the implementation of inclusive education at tertiary level in Zimbabwe and elsewhere in the world.
\end{abstract}

Keywords: Inclusive education, exceptionalities, intervention, rehabilitation, Salamanca Report, tertiary institution, mainstreaming, institutionalization, integration

\section{Background to the Study}

The development of Education and Training in Zimbabwe has undergone many phases since the advent of independence in 1980. As massive changes unfolded on the educational landscape after 1980, the aspect of inclusive education also became a topical issue. Thus the concept of inclusive education evolved from mainstreaming to institutionalisation, rehabilitation and integration. Mainstreaming were efforts to provide specialist services for exceptional learners in the least restrictive environment, (Kirk and Gallagher, 1983). The exceptional learner was placed in the same classroom with his/ her normal peers but at the same time receiving special services in that regular class. Mainstreaming was done in an effort to create as normal as possible a learning and social environment for students with exceptional conditions. After mainstreaming came institutionalisation where students with exceptional conditions were rehabilitated in special institutions away from the ordinary school in their home environments. This was preceded by integration. In this context the SWD was expected to adjust and adapt to the school environment as a visitor, (Fisher, Shumaker and Deshler, 1995). However, of significance to note is that during the period of mainstreaming and integration, there was concentration on and bias towards learners with physical disabilities only. As alluded above learners with visual and hearing impairment were relegated to special institutions. Integration to a larger extent focused on the enhancement of students' social development. Wadron, Cole and Majd, (2001) assert that these earlier descriptions of inclusion framed it as a special education issue. Special classes were principally developed as a place for students who could not keep pace with fellow classmates. How ever the special education perspective did not bring the desired outcomes for it emerged that educating students with special needs in isolated settings carried with it an element of discrimination and social exclusion. It is against this background that this study was conceived. Having observed the shortcomings of mainstreaming and integration this paper attempts to showcase a host of attendant issues around the concept of inclusive education. 


\section{Statement of the Problem}

Tertiary institutions are compelled by the constitution of Zimbabwe to be inclusive in every respect as they discharge their mandate. This ranges from recruitment of student teachers to institutional compatibility in terms of infrastructure, welfare provisions at college and deployment. The rapid developments in the field of inclusive education, have therefore brought in insurmountable challenges particularly to tertiary institutions as the scope of their operations has become broadened to embrace this concept. The study focuses on evaluating the extent to which tertiary institutions in Zimbabwe are meeting the diverse requirements for successful implementation of inclusive education.

\section{Objectives for the Study}

A number of objectives were developed to guide the study. These are presented below as follows:

- To review landmarks in the evolution of inclusive education in Zimbabwe and elsewhere in the world.

- To examine the intervention strategies employed by tertiary institutions in their quest to implement inclusive education.

- To attempt a critical appraisal of the benefits of inclusive education.

- To engage a case study analysis of an institutional response to the requirements for implementing inclusive education.

- To interrogate adaptive mechanisms tailored to improve the implementation of inclusive education in Zimbabwe and elsewhere in the world.

\section{Literature Review}

\subsection{Conceptualising Inclusive Education.}

This section profiles definitions of inclusive education from a variety of perspectives. It is hoped that these definitions would leave the reader with a clear conceptual exposition of inclusive education. However it must be acknowledged that: whether we are talking about a school, college or and tertiary institution the same principles of inclusivity apply. Bui, Quirk, Almazan, Valent, (2010); Alquiraini \& Gut, (2012) report that inclusive education is when students, regardless of any challenges they may have, are placed in age appropriate general education classes that are in their own neighbourhood schools to receive high quality instruction, interventions and supports that enable them to meet success in the core curriculum. Elaborating on the same subject Alquiraini \& Gut (2012) underpin the fact thatthe school and classroom operate on the premise that students with disabilities (SWD) are as fundamentally competent as students without disabilities. UNESCO (2009) views inclusive education as "....a process of addressing and responding to the diversity of needs of all learners through increasing participation in learning, cultures and communities and reducing exclusion from education and within education'. As a categorical imperative the whole education system should embrace the challenges and benefits of diversity. In addition, emphasis is on every individual meeting success regardless of whether one has disabilities or not.

IEC (2017)adds other dimensions to our conceptual appreciation of inclusive education. To this IEC reveals that inclusivity means all students attend and are welcomed by their neighborhood schools in age appropriate regular classes and supported to learn, contribute and participate in all aspects of life of the school. The major thrust of inclusive education according to the source alluded above is to develop and design schools, classrooms and activities that promote the learning and participation of all students together. In resonance with submissions made earlier on, IEC (2017) asserts that inclusive education is about ensuring access to high quality education for all students by effectively meeting their diverse needs in a mutually supportive school climate. Fundamental to the dispensation of inclusive education is the quest to diminish and remove barriers and obstacles that may lead to exclusion. IEC (2017) unveils what it terms critical components of an inclusive/common learning environment. The components embrace: classrooms, libraries, gym, performance theatres, music rooms, computer rooms, cafeterias, playgrounds and the local community. Thus students with disabilities need not too learn in isolation from their peers. According to Haque (2014) inclusive education happens when children with and without disabilities participate and learn together in the same classrooms. Research has consistently demonstrated the positive outcomes that are associated with a child with disabilities attending classes alongside peers who do not have disabilities, (MacManis, 2017). However merely placing children with and without disabilities together is not a guarantee for positive outcomes, in the absence of advocacy, systematic planning, support and commitment. Inclusive education is about children with disabilities- whether the disability is mild or severe, hidden or overt-participating in everyday activities, just like they would do if their disability were not present, (Bui, Quirk, Almazan $\&$ Valenti, 2010). In the final analysis quality inclusive education is premised on but not confined to the following guiding principles: all children belong; all children learn in different ways and more significantly every child has the right to be included.

Inclusive education has been explained from different vantage points. An attempt is made hereunder to unpack the above conceptual expositions of inclusive education. Thus, below are crisscrossing themes and observations discerned from the foregoing discussion?

- Education is a basic and universal right for all children-with or without disabilities.

- Children as individuals are endowed with unique and differentiating characteristics.

- Normality and exceptionality are all found on a continuum of individual differences. This continuum has implications for individualised educational programming.

- The uniqueness of individuals apply to both students with and without disabilities and this in turn predispose them to different learning styles. 
- Research findings have proved enormous benefits for inclusion while there is no evidence to the contrary.

- Marshalling all students with or without special needs, to a common school in their neighbourhood has become the hallmark for inclusive education.

\subsection{Landmarks in the Evolution of Inclusive Education}

This section attempts to proffer landmark developments in the evolution of inclusive education both from the international and Zimbabwean perspectives. The thrust is to review the legal and technical frameworks that gave impetus to the adoption of inclusivity as a distinct feature of the education dispensation in Zimbabwe. The United Nations (UN) has assisted developing and developed nations to embrace inclusivity by promulgating a number of international declarations and conventions that informed this study. Zimbabwe became a signatory to these conventions and in addition also committed itself to implementing inclusive education through Acts of Parliament and Statutory instruments. Thus hereunder the paper gives a synopsis of these international and local antecedents to the adoption of inclusive education in Zimbabwe.

From a legislative and technical point of view the motions towards inclusivity in Zimbabwe are traceable to The Education Act of 1987 (revised 2006).The Education Act has a non-discriminatory clause which promote equal access to education regardless of the unique characteristics of learners across the education landscape. This was done to bring relief to the bulk of learners who had suffered systematic marginalisation and discrimination particularly during the colonial era. Up until 1980 the bulk of African children whether with or without exceptionalities had been exposed to overt discrimination by the minority white regime. The provisions of the Education Act resonated well with what was to be known as the Jomtien Declaration (1990) on education for all (EFA). This declaration among other things states that education is a fundamental right for all people. By then it noted that the current provision of education was seriously deficient and needed to be more relevant, qualitatively improved and made universally accessible. Article no. 1 of the said declaration highlights that "......every person, child, youth, adult shall be able to benefit from educational opportunities designed to meet their basic needs." The same declaration also noted that the removal of obstacles that hamper their active participation must be ensured and a commitment made to remove disparities and avoid discrimination. The landmark declaration also underpinned the need to understand the: poor, street and working children, remote populations, nomads, migrant workers, racial and linguistic minorities, refugees etc. Thus the diversity, complexity and changing nature of basic learning needs necessitate broadening and constantly redefining the scope of basic education. Integration and participation that came on board as result of the Jomtien Declaration represented well tested and cost effective approaches in the quest to promote equal access for all those with special educational needs as part of a nationwide strategy aimed at achieving the universal goal of education for all, (EFA). The declaration also focused on inclusive education and recommended that schools should accommodate all children regardless of their physical, intellectual, social, emotional, linguistic or other conditions. Zimbabwe ratified the Jomtien Declaration. However in order to give effect to the provisions of the Jomtien Declaration Zimbabwe proceeded to promulgate the Disabled Persons Act of (1992). The Act enjoined all institutions and government agencies at all levels to act within the limits of resources available to them to assist persons with physical or mental disabilities to achieve their full potential and also minimise the disadvantages emanating from their unfortunate circumstances. However this was still a long way before inclusivity in its entirety could gain traction on the Zimbabwean educational landscape in general and tertiary institutions in particular. As a precursor to complete overhaul of the education system in Zimbabwe, in favour of inclusivity, several other international and local paradigms where enunciated that informed both the theory and practice of education.

Another watershed development on the international arena that bolstered efforts and moves towards inclusive education was the famous UNESCO (1994) Salamanca Report. The Salamanca Statement urged allcountries that ascended to it to adopt as matter of law or policy the principles of inclusive education. The Salamanca Report was a culmination of a world conference on special needs education: access and quality held in Spain, 7-10 June in 1994. UNESCO (1994 p.iii) indicates that, "The conference adopted the Salamanca Statement on Principles, Policy and Practice in Special Needs Education and a Framework for Action. These documents are informed by the principles of inclusion, by recognition of the need to work towards schools for all, institutions which include everybody, celebrate differences, support learning, and respond to individual needs." Arguably the international conference held in Spain's city of Salamanca formed the bedrock for adoption of inclusive education at global level. However the impact of this conference was quick to influence the trajectory of events on the Zimbabwean educational landscape.

On the local scene in1998, the then president of the republic of Zimbabwe, R. G. Mugabe appointed a commission of inquiry into education and training (CEIT). The commission was headed by professor Nziramasanga. Thus the Nziramasnga Commission of inquiry (1999) recommended that an inclusive type of education be adopted for the country at all levels of the education system and that all teachers and lecturers be trained on special education. A decade later in 2009 UNESCO further provided a conceptual framework for understanding inclusive education. It defined inclusion as a process of addressing and responding to the diversity of needs of all children, youth and adults through increasing participation in learning, cultures and communities and reducing and eliminating exclusion within and from education. However on the local scene the initiative that gave further momentum to inclusive education was the Zimbabwe Agenda for Sustainable Socio Economic Transformation ZIMASSET (2014-2018). It set a vision for articulating inclusive education at tertiary level. In general ZIMASSET's vision was Torwards an Empowered Society and Growing the Economy'. However, the Division of Tertiary Education Programmes (2014-2018)prioritised improvement of access to tertiary education through E-learning programmes and inclusivity. 
4.3. Intervention Strategies Employed By Tertiary Institutions in the Quest to Implement Inclusive Education: The Case of Masvingo Teachers College: Zimbabwe

The foregoing discussion has proffered the conceptual exposition of inclusion from a variety of perspectives. It was incumbent upon the researchers to examine whether Masvingo Teachers' College had the same understanding of the term inclusion as construed in broader educational circles. Pursuant to this undertaking guidelines developed by Prater (2003) were used as a yardstick to appraise Masvingo Teachers' College's thrust towards inclusive education. For instance it was found that the range of exceptionalities embraced were but not restricted to: sensory problems, emotional and behavioural problems, speech challenges, albinism, the slow and gifted learners, students with health problems and those from poor backgrounds. Thus the focus was on the learner's characteristics and how the institution can intervene to handle the different learning exceptionalities. A salient observation was that during mainstreaming and integration teacher training colleges in Zimbabwe had no specific intervention strategies to guide the drawing up of syllabi blueprints with an inclusive dimension. By the time of this study, inclusive education was not treated as an independent discipline but rather thinly infused into Professional Studies Syllabus A and Theory of Education. This goes to explain how narrow the scope of implementation of inclusive education was, both at the process and product levels of the college's engagement.

However, the ambitious policy pronouncements by Masvingo Teachers' College were derived more from the political than the technical environment. This in part explains why there are no distinct intervention strategies beyond the seemingly plausible pronouncements on paper. In this connection the college's inclusive education policy was conceived in response to one of the goals set out in the ZANU (PF) 2013 Election Manifesto that referred to the call for 'Education for All'. The same principle seemed to underlie the post 2013 economic and national development blueprint, ZIMASSET (2014-2018). ZIMASSET was a cluster based economic plan envisioned to exploit the internal linkages of various sectors of the economy. Thus in response to these political developments in the country Masvingo Teachers' College attempted to craft syllabus documents that endeavoured to create an inclusive college environment that catered for both staff and students without compromising quality. At policy level the college outlined its inclusive education vision with regards to its various subsystems such as, Academic Study, Theory of Education, Early Childhood Development, Professional Studies, Health and Life Skills Education and Computer Studies. The college had in principle introduced inclusive education through curriculum reforms. The main focus of syllabi documents was on curriculum, environment, accommodation, enrolment, continuous professional development, research and development, coordination structure, human and financial resources and talent development of staff and students. In addition to these curriculum reforms the college also mounted an institution wide sensitisation workshop on inclusive education. By the time of this study the trend at Masvingo Teachers' College on inclusive education was rather cosmetic because focus was restricted to students with mild physical disabilities at the expense of other conditions of exceptionalities for example profoundly deaf and blind. To this end it follows that students with and without exceptionalities were exposed to uniform treatment without deliberate modifications and interventions to cater for diversity. Hence, it can be noted from the foregoing discourse that there were no clear intervention strategies in the implementation of inclusive education at MTC, beyond mere policy pronouncements. Nonetheless more information would be unveiled on the college's thrust on inclusive education from an analysis of field data.

\subsection{Benefits of Inclusion}

MacManis, (2017) outlines the benefits of inclusion from three vantage points. The first perspective shows that, "...students with disabilities have a higher achievement and improved skills through inclusive education, and their counterparts benefit, too." The second perspective relates to benefits for SWD. In this regard the advantages include but not confined to: academic gains in literacy, maths, and social studies, better communication skills and improved interpersonal skills, fewer absences and referrals for disruptive behaviour. Third and final perspective shows that for their peers without disabilities they tend to develop more positive attitudes in the arrears alluded above when in inclusive classrooms. Over the past three decades research has demonstrated that inclusion gives non-SWD new kinds of learning opportunities. One of these is when they serve as peer-coaches resulting in the significant improvement of their own performance.

It has been observed that inclusion is a way of reaching out to all children of school going age including the marginalised in the mainstream schools alongside their counterparts where there is commitment to removing all barriers. There are marginalised people like those with albinism who in the face of social and cultural challenges would not even think of going to school as their condition is often misunderstood. In Zimbabwe albinism is a source of mockery, discrimination, prejudice and in most cases fear and violence. Hence the concept inclusion depicts an effort to make sure that diverse learners, that is those with different: disabilities, conditions, cultures, family backgrounds and learning styles are exposed to teaching strategies that reach out to them as unique individuals (McMillan and Shumaker, 2010). A widely held view is that schools should be places where barriers are removed and have all learners feel accepted and loved ((Jomtien, 1990). Diversity aims to recognise, respect and value people's differences to contribute and realise their full potential by promoting an inclusive culture for all staff and students. Thus to have a truly diverse universal community requires an inherent commitment demonstrated through a perception and actions that recognise and values these differences. Research findings have attested to the fact that most students learn and perform better when exposed to the richness of the curriculum as long as appropriate pedagogical strategies are applied. The learning environment in most cases seem not to be as friendly as it should be. Kliewer and Biklen (2001) found out that inclusive learning environments facilitate the acquisition of literacy and adaptive skills such as students' social relationships. In the same vein Roy (2003) observed that no studies since the 1970s have demonstrated any notable negative consequences of inclusion. Thus 
inclusion has been proven not to compromise the general educational outcomes among a mix of SWD and those without. Research evidence on inclusive education shows that everyone wins and no one loses. It could be concluded from these studies that in inclusive learning settings, diverse learners can still meet individual needs more effectively while working together with their counterparts. The other benefit of inclusion lies in the operationalization of what has come to be known as the inclusive service environment.

According to Barker, Wang \& Walberg, 1994 an inclusive service environment is more than ensuring an accessible building, providing a sign language, an interpreter or creating large print documents. Rather an inclusive service environment accommodates all people not just students regardless of their learning exceptionalities. It uses their skills and strengthens their abilities. Thus an inclusive service environment is respectful, supportive and equalising. Actions and attitudes of people who are already in the service environment provide the bedrock of inclusion. For instance a programme manager who thinks first about what someone can do is more likely to be more inclusive than one who focuses on an individual's limitations. The underpinnings of an inclusive service environment are access, opportunity, independence and dignity. An inclusive service environment places a high price on unique characteristics of individuals. Ultimatelyan inclusive service environment must meet the basic accessibility standards to the greatest extent possible in terms of pathways, ramps, doors, restrooms, kitchens, library facilities, offices, toilets, accommodation and other adaptive environmental and technical facilities. Finally inclusion has also been found to promote equality and eliminate discrimination in education. From the above observations it suffices to say that the many benefits of inclusive education tend to underpin the assumptions underlying the many international declarations and locally crafted statutes that gave momentum to the full implementation of the concept.

\section{Research Methodology}

\subsection{Research Design}

A case study research design was adopted for this investigation. The researchers drew insights from the definition proffered by Greig, Tailor and Mackay (2007) who defined a case study as an investigation of an individual, a family, a group, an institution, programme or intervention. The case study research design was deemed most appropriate for studying contemporary phenomenon as well as getting to the bottom of the matter under spotlight, (Gilham, 2000). Masvingo Teachers' college as a tertiary institution became the focal point of this inquiry. The thrust of the study was to explore the intervention strategies the college had adopted in its quest to implement inclusive education. Thus the researchers were keen to make an intense analysis of the situation on the ground in order to gain an authentic picture of what was happening at the institution under spotlight and extrapolate the findings to tertiary institutions nationwide.

\subsection{Sample and Sampling Procedure.}

A non-probability sample was generated for the purposes of this study. Thus participants to this research study were purposively sampled for feasibility and practicability purposes, (McMillan and Schumacker, 1993; Bryman, 2012). The sample comprised 30 students and 20 members of staff, bringing the total number to 50 . Students who participated in the study were drawn from intakes nine $(\mathrm{N}=15)$ and ten $(\mathrm{N}=15)$. College staff who participated were broken down as follows: Vice principal $(\mathrm{N}=1)$, dean of students $(\mathrm{N}=1)$, Head of Teaching Practice Department $(\mathrm{N}=1)$, Kitchen Supervisor $(\mathrm{N}=1)$, Sports Director $(\mathrm{N}=1)$ Main subject coordinators $(\mathrm{N}=9)$ and general working staff $(\mathrm{N}=6)$. Both the college Staff and Students selected for this investigation constituted highly heterogeneous groups in terms sex distribution, age ranges, levels of education and length of professional experience. Student teachers approached included those with and without exceptionalities.

\subsection{Instrumentation, Data Presentation and Analysis}

The principal data collection instruments for this study were: the questionnaires in their varied form, interview schedules and documents review (Borg and Gall, 1986). The questionnaires allowed the researchers to rapidly collect the data sought with time and effort efficiency. The researchers were responsible for administering the questionnaires as well as conducting both the interviews and documents review. It was on the basis of data generated from the three sources that a critical analysis was undertaken to unpack key messages that emerged from the study, (Neuman, 2000; Gilham,2000). Mainly data were analysed from the qualitative research paradigm, but with occasional recourse to the quantitative dimension. Thus major findings of the study are presented in the upcoming discussion.

\subsection{Delimitations and Limitations of the Study}

The study involved collection of theoretical and empirical data. Thus field data was elicited from Masvingo Teachers College located in Masvingo Province in Zimbabwe. Focal areas that underpinned the study were the: conceptual framework, history, intervention strategies and benefits of inclusive education. Treatment of these issues was complemented by an in depth case study analysis of MTC as an aid to understanding the thrust of inclusive education in Zimbabwe's Tertiary institutions. The other crucial delimiting and limiting factor were the instruments used to collect desired information which embraced questionnaires, interview schedules and documents that were reviewed. The study was based on a sample of 50 participants. Thus given the fact that only one institution was the focal point of this investigation interpretation and generalizability of study findings would have to be done with great caution and reservation.

\section{Findings and Discussion}


This section looks at the scenario at Masvingo Teachers College. It was envisaged that the situation at this case study institution would give us a glimpse of an institutional response to the requirements for implementation of inclusive Education. Data were collected through questionnaires, interviews and documents review from a wide cross section of students, lecturing and non-lecturing staff of MTC. The data were subsequently analysed to discern major trends depicted. Coordinators of main subjects were the first respondents to the questionnaire. It was interesting to observe that on whether they were comfortable with the concept of inclusion or not, the response was $100 \%$ affirmative. On another note ninety-five percent of main subject coordinators also conceded that they were comfortable with the benefits of the concept of inclusion. In defending their position they revealed that social and psychological benefits were associated with inclusion comparable to the idea of special schools. In extending their argument they further hinted that the benefits of inclusion played in favour of both the students with and without exceptionalities. However the temptation was to believe that lecturers at this particular college would not accept the idea of inclusion since there was nothing on the ground to support its adoption at the college. Question 3 sought to find out whether subject coordinators chose main subjects for students with exceptionalities. Hundred percent (100\%) of the respondents acknowledged that a uniform approach was used for both categories of students alike. They insisted that college policy dictated that main subject allocation was done on the basis of which subject had the student passed better at $\mathrm{O}^{\prime}$ level, and that this information was readily available on all students' application forms.

Questionnaire items 4-10 yielded data that highlighted glaring challenges with regards to the compatibility of college infrastructure and facilities to the diverse needs of students with exceptionalities. About $95 \%$ of main subject coordinators at Masvingo Teachers College revealed that for the majority of students with exceptionalities their condition was exacerbated by poverty. However poverty as a basic underlying challenge affecting the generality of all students placed a heavy burden on students who chose practical subjects as their main studies. Practical subjects required extra funding to purchase materials needed to meet the practical component. In these instances SWD tended to be more vulnerable than their other counterparts without challenges. Apart from the above highlighted problem students with disabilities were also confronted with a host of other predicaments. For instance students on wheelchairs found it difficult to easily access lecturers' offices for the purposes of consulting for Curriculum Depth Study (CDS). To circumvent this problem, lecturers had to leave their offices to attend to such students in lecture rooms. Similarly the same students had problems in gaining entry into libraries, since there were no ramps adapted to both lecturers' offices and library facilities. The affected students indicated that their colleagues assisted them to gain entry into the library and to access books located on high shelves. Coordinators of main subjects also noted the problem of speed and accuracy when undertaking practical subjects, among students with exceptionalities. The lecturers were forced to grant these students more time to ensure task accomplishment. Pedagogical challenges were also imminent when the college recruited students with diverse needs and from varied backgrounds. For instance the partially sighted and those with a single hand only, found it difficult to accomplish tasks perfectly. Resources needed to facilitate adaptive mechanisms in their examinations proved extremely expensive as well. Subject coordinators, nonetheless noted that isolating these students was not an option as they were expected to compete with their counterparts without exceptionalities on the same wavelength.

SWD were also issued with questionnaires to which they responded. Hundred percent $(100 \%)$ of respondents indicated that the college social environment was quite favourable in terms of attitudes of students, lecturers and non lecturing staff. This was more likely to be the case following a sensitisation workshop on inclusive education that was held for the entire college staff. Question 2 had elicited data on whether students with exceptionalities benefited from their coexistence with students without challenges. Mixed responses were observed. However $90 \%$ of the respondents revealed that they benefited academically, socially and psychologically. This group further contented that they gained confidence from the setting of inclusion because of peer and staff acceptance. By contrast $10 \%$ noted that they did not benefit much from the so called 'normal students' as these tended to look down upon them. Inherent feelings of inferiority are usually a challenge to people with exceptional conditions. On the other hand some people are naturally afraid of people with albinism. Such circumstances are more likely to confound the situation, with the affected feeling socially marginalised. Question 3 sought to determine whether students with exceptionalities engaged in other activities besides academic work. The majority, $80 \%$ stated that they were involved in sports. This could be the case because the college offered a variety of sporting disciplines including Paralympic games thus accommodating all in sports. It was found out that the college assigned a lecturer to coach Paralympic games, hence students with exceptional conditions enjoy regular sports as well as going for competitions up to national level like everyone else. This raised their morale and confidence within an inclusive college climate. The minority $20 \%$ maybe could not engage in sports on account of acute physical challenges. Question 4 wanted information on whether the necessary provisions were made for students with exceptional conditions to cope with their academic work. Once again the majority 95\% indicated that such provisions were largely missing in the college. Elaborations on this point were made. For instance students in this unique category who performed below average exposed that they were made to rewrite assignments without follow up assistance. They further revealed that the tendency by most lecturers was to purport to be too busy and refer the affected students to the library to research again on failed topics. Question 5 sought information on exceptional students' perceptions on adequacy of infrastructural arrangements for them to operate comfortably within the college environment. In this connection the students raised concerns over inappropriate pathways, inaccessibility of offices \& library, insufficient hostels, shortage of toilets and other specialised learning facilities.

The vice principal of Masvingo Teachers College responded to a 5 item interview schedule. An enquiry was made as to whether he kept a record of students with exceptionalities. His response was affirmative and presented documentary evidence. Review of documents seen indicated that he had categorised this group of students as thus:

- The physically challenged. 
- The intellectually challenged.

- Albinos

- Those with sensory problems

- Those with acute health conditions

The researchers were able to go through the lists of names of students under the various categories alluded above. However a striking observation was the conspicuous absence of students with visual and hearing impairments. This in the view of researchers compromised the college's ability to fully implement inclusive education. Rampancy of children of school going age with these peculiarities attested to the need to train teachers who should deal with pupils with such conditions. Regarding the issue whether their advertisement for aspiring students was inclusive, the vice principal alluded to the fact that the college simply flighted the required qualification specifications for college admission so that eligible incumbents can forward their applications. Though he professed bias towards selecting candidates with exceptionalities, it seems it was difficult for interviewers to competently identify some peculiar conditions without the full disclosure of the affected students. This inadvertently disadvantaged some aspiring students who were expected to be enrolled if their condition had been known. Reacting to the question on the college's thrust in the implementation of inclusive education, the vice principal admitted that the college lacked adequate facilities and resources. In this connection he conceded that though reasonable ground had been covered, a lot more needed to be done to ensure the college became an ideal destination for students with various exceptionalities. The respondent only cited the construction of ramps that was underway as one of the innovations the college had mooted to promote inclusivity. However an inspection of the ramps revealed that they(ramps) looked to be substandard and too steep making it difficult for students in wheelchairs to go up and down. As a result the ramps had caused some accidents.

The researchers further carried out document analysis to determine conformity of college syllabus documents to inclusive education. It was impressive to observe that the college syllabuses clearly articulated: the background, definitions, vision and historical development of inclusive education. Declarations on inclusion made at different fora were clearly outlined as well. The contextual background of how the concept of inclusion came into being was clearly proffered in the syllabus documents. Consequently the syllabus documents analysed were very inclusive in nature. The vice principal admitted that if the syllabus documents in their current form were to be fully implemented with an adequate backing of resources an inclusive college environment would be achieved. He further revealed that Masvingo Teachers' College had its own strategic plan to come up with specialist rooms and resource units. Overall the vice principal demonstrated an unequivocal commitment to his college's vision for implementing the concept of inclusive education.

A very brief and informal interview was held with the dean of students, mainly for the purposes of validating findings early in the research. The dean of students was found in possession of information and statistics on SWD that corresponded with the database in the vice principal's office. This attested to the fact that both the vice principal and the dean of students were working closely together on the issue of inclusive education in the college. She revealed that allocation of accommodation was prioritised in favour of students with physical challenges and those in wheelchairs. These were usually allocated rooms on the ground floor to avoid obvious challenges associated with going up and down the stairs. Though pregnancy was an exceptional condition, the dean of students said it was college policy not to give this category of students' accommodation. However the college was on record giving free lunch to non-resident students who were HIV positive, diabetic and had other acute health conditions.

A submission was also sought from the kitchen supervisor. Quite interesting observations were made on how students with exceptionalities presented themselves in the dining hall. He noted that in some instances diabetic students jumped the queue as they thought it was their right to be saved first. However the rest of other students according to the kitchen supervisor behaved fairly normally because they were positive about their condition. He attributed this attitude to the mass coverage of these conditions by public media and the wholesome reception these students got at college. The college's counselling programme, he indicated was on course to orient these students during the initial days of their stay at college. The health and life skills department superintended over this programme. Alongside the kitchen supervisor, grounds people were also informally interviewed on the concept of inclusion. So interesting were the results. Eighty percent $(80 \%)$ of the respondents in this category professed ignorance on the issue of inclusive education, despite a college wide sensitisation workshop on inclusivity. Most general hands admitted that they did not follow the proceedings of the sensitisation workshop quite closely. The researchers were not surprised because this category of college workers is staffed by predominantly illiterate to semi-literate personnel.

The last point of call was the Teaching Practice Department. The Head of the Teaching Practice Department revealed that students with exceptionalities were blended with the rest of ordinary students. This was designed to ensure these students get assistance from their colleagues. The head of the teaching practice department was also quizzed on other considerations she made when deploying students with challenges. She indicated that students who were physically challenged were given first preference in terms of schools with water, electricity and near the road. This was meant to make life more comfortable for such students as they would not travel long distances to get transport, water and firewood. In addition it was also pointed out that students with health problems were also placed near hospitals and clinics. The TP head was asked on measures the college engaged in dealing with students with exceptionalities, but were potential distinction material. Her submission revealed that the TP department placed such students on a special supervision programme, thus rendering them the much needed positive encouragement, emotional support and technical assistance. Again in circumstances where a student performed below expectation, the college would not be vindictive as it would be with ordinary students. Students with exceptionalities received more systematic, extended, guided and sustainable assistance that attempted to address the performance inhibiting factors. In spite of the seemingly notable initiatives and general propensity towards inclusive education, Masvingo Teachers College was still a long way to achieve inclusivity. 
Inadequate funding remained the basic underlying factor behind deficiencies in facilities and infrastructure needed to achieve inclusivity at the institution.

\section{Summary}

The fulcrum of the study was to interrogate the scope of intervention strategies employed by tertiary institutions in their quest to implement inclusive education in Zimbabwe. Due to feasibility and practicality considerations a case study research design was adopted for the study. In addition a non-probability sample of 50 participants was drawn from the college's staff and students. Research instruments that were operationalized to elicit the required data encompassed a structured questionnaire and an interview schedule. Documents review yielded data that complemented questionnaire and interview data. The major finding of the study depicted Masvingo Teachers' college, which was the focal point of this investigation as being ill prepared to engage a full swing implementation of inclusivity against a bedrock of a poor resource and technical base.

\section{Conclusions}

A number of conclusions derived from the study are thus chronicled below as follows:

- The call for inclusive education is premised upon the conviction that education is a universal right for all people (Jomtien Conference 1992; Salamanca Report 1994).

- Inan inclusive educational setting individual learners meet diverse needs through working together at the same time promoting equality and eliminating discrimination in education.

- At the time of the study empirical evidence pointed to tertiary institutions being extremely behind in terms of meeting basic requirements for implementing inclusive education. The case study of Masvingo Teachers' College gives credence to this assertion.

- Masvingo Teachers' college, however committed on paper, seriously lagged behind in its quest to implement inclusive education.

- Inappropriate infrastructure, inadequate specialised technical facilities and support services militated against the implementation of inclusivity at Masvingo Teachers' college and other tertiary institutions in Zimbabwe.

- Underlying the major challenges to the implementation of inclusive education in Zimbabwe's tertiary institutions was the perennial problem of stakeholder and governmentfunding.

\section{Recommendations}

Tertiary institutions are faced with a mammoth task to overcome the insurmountable challenges associated with implementing inclusive education in Zimbabwe. Both the current study findings and conclusions have pointed to glaring economic and technical factors underlying the lack of progress in achieving inclusivity. Thus below is a raft of propositions envisioned to significantly impact positively towards increasing the momentum of inclusive education implementation in Zimbabwe's tertiary Institutions.

- CIET (1999) recommended the adoption of an inclusive type of education at all levels of the education system. In tandem with this prerogative is the need to train all educational personnel through pre-service and in-service programmes to attune it to the requirements for implementing inclusive education.

- In addition to the above, tertiary and other institutions are enjoined to accommodate all students regardless of their physical, intellectual, social, emotional or other conditions.

- For inclusive education to gain traction on the ground, it is proposed that the lecturer: student ratio be revised downwards to allow for more intensive and comprehensive attention to the diverse needs of all students, with or without disabilities.

- Masvingo Teachers' College and other tertiary institutions in the country must engage a synergy of a wide range of education partners, private business community, public sector, non-governmental and international multilateral organisations and other relevant stakeholders to fund the implementation of inclusive education in Zimbabwe.

- Advocacy programmes for inclusivity should be a continuous process to change the mind-set of the whole cross section of society for all and sundry in favour of this contemporary educational initiative. The section on benefits of inclusion above refers.

- Tertiary institutions should put in place a long term human resources development programme to orient staff to appreciate and implement the concept of inclusion not as a separate phenomenon, but as an integral part of their professional dispensation.

- All tertiary institutions have to revamp their infrastructure and facilities in tandem with the requirements for the diversity and litany of students with exceptional needs and conditions. This may entail the construction of specialist rooms, facilities upgrade and the relevant technological and technical installations.

- Material resources and equipment consistent with the different exceptionalities of inmates in tertiary institutions should be mobilised.

- Complementary to the above, tertiary and other institutions of learning should adopt pedagogical and andragogical paradigms consistent with inclusive educational settings.

- The Zimbabwe government is enjoined to be more pragmatic and proactive in national policy development and oversight role to ensure uniform approach to the implementation of inclusivity as well as setting up time-framed targets, developing yardsticks for evaluating progress and overall coordination of the inclusive education initiative at national level. 


\section{Scope for Further Research}

Leedy (1985 p.61) reveals that an investigator cannot research all aspects of a problem. Thus the current study sought to unravel the intervention strategies employed by tertiary institutions as they grapple with the implementation of inclusive education in Zimbabwe. The research had a case study of Masvingo Teachers' College as its point of anchorage. Consequently the scope of the study was rather limited in terms of variables and population covered. Other progressive scholars are therefore challenged to extend or replicate the same study at regional or national levels to improve upon both the utility, validity and generalizability of results. It would be of academic interest to interrogate the inclusive education concept in its wider context to find out if trends and patterns depicted by the foregoing study are affirmed or rejected.

\section{References}

i. Alquiraini, T. \& Gut, D. (2012). Critical components of successful inclusion of students with severe disabilities. International Journal of Special Education, (2012) Vol. 27 No.1 p42-59.

ii. Barker, E. T., Wang, M. C. \& Walberg. H. J. (1994). The effects of inclusion on learning: Educational Leadership, 52 (4), 33-35.

iii. Borg, W. R. \& Gall, J. P. (1986). Educational Research: An Introduction. New York: Longman

iv. Bryman. A. (2012) Social Research Methods. (4th Ed). Oxford. Oxford University Press

v. Bui, X., Quirk, C., Almazan., \& Valenti, M. (2010). Inclusive education research and practice: Inclusive works. Hanover. MD: Coalition for Inclusive Education. Retrieved from teachingcommons.cdl/ tk/modules.../inclusion_TKModule_PPT 3.2016_000pdf

vi. Bui, X., Quirk, C., Almazan., \& Valenti, M. (2010). Inclusive Education: Definition, Examples, and Classroom Strategies. Retrieved from https:// parkbench.com/...inclusive-education-definition-examples-and-classroomstrat...

vii. Fisher, J. B., Shumaker, J. B., \& Deshler, D. D. (1995). Searching for validated inclusive practices: A review of literature. Focus on exceptional children. 28 (1) 1-20

viii. Government of Zimbabwe. (1987, 2006). Education Act, Amended 2006. Harare: Government Printers.

ix. Gillham, B. (2000). Case Study Research Methods: Real World Research. New York: Continuum.

x. Government of Zimbabwe. (1992). Disabled Persons Act. Harare. Government Printers

xi. Government of Zimbabwe (2013).The Constitution of Zimbabwe. Harare: Government Printers

xii. Government of Zimbabwe. (2013). Zimbabwe Agenda for Sustainable Socio Economic Transformation (20142018). Harare: Govt Printers

xiii. Greig, A., Taylor, J. \& Mackay, T. (2007). Doing Research with children. (2nd Ed). London: Sage Publishers.

xiv. Haque, E. (2014). Special and Inclusive Education in India: An Interpretation and Implementation. Journal of advances and Scholarly Researches in Allied Education. Vol. viii, No. xvi, October, 2014 ISSN. 2230-7540.

xv. IEC, (2017). What Is Inclusive Education? Retrieved from HTTP:/ INCLUSIVEEDUCATION.CA/

xvi. Kirk, S. A., \& Gallager, J. J. (1983). Educating exceptional children. Boston: Houghton Muffin.

xvii. Kliewer, C. \& Biklein, D. (2001). Journal of the association for persons with severe handicaps. (JASH). Vol 26 p1-25.

xviii. McManis, L. D. (2017). Inclusive Education: What It Means, Proven Strategies, and a Case Study. Retrieved from https:/ / education-cu-portland.edu/ blog/ classroom-resources/ inclusive-education/

xix. McMillan \& Schumaker (2010). Research in Education. Evidence Based Inquiry. (7th Edition). Virginia: Commonwealth University.

xx. Masvingo Teachers' College, (2014) Inclusive Education Syllabus Documents.

xxi. Nziramasanga Commission of inquiry, (1999). Report on the Presidential Commission of inquiry into Education and Training. Harare: Government Printers.

xxii. Neuman, W. L. (2000).Social research methods qualitative and quantitative approaches. $4^{\text {th }}$ Edition. Boston: Allyn and Bacon, Needham Heights.

xxiii. Prater, M. A. (2003). She will succeed: Strategies for success in inclusive classrooms. Teaching exceptional children. 35 (5) 58-64.

xxiv. Roy, A. (2003). A comparative study of special education in India and China. DOI 10.5353/th b2774194 Retrieved from https:/ / www.researchgate.net.../29834805_A comperative study_of special education...

xxv. UNESCO, (1990). World Declaration on Education for All, Jomtien Conference, Thailand. (BICE). 5-9 March, 1990

xxvi. UNESCO. (1994) The Salamanca Statement and Framework for Action on Special needs Education: Adopted by The World Conference on Special Needs Education: Access and Equality. Salamanca, Spain, 7-10 June 1994

xxvii. UNESCO, (n.d). Interview with the UNESCO-IBE Director, Clementina Acedo. International Bureau of Education. Retrieved from www.ibe.unesco.org/ fileadmin/ user...Kit/ interview_clementina_Eng13Nov.pdf

xxviii. Waldron, N. E., Cole, C. and Majd, M. (2001). The academic progress of schools across inclusive and national settings: A two year Indiana Study. Bloomington, IN: Indiana Institute of Disability and Community.

xxix. Zimbabwe African National Union, (2013) Election Manifesto. Harare: Jongwe Printing Press

xxx. Ainscow, M. \& Cesar, M. (2006). Inclusive education ten years after Salmanca: Setting the agenda. European Journal of Psychology of Education, XXI, 3 pp.231-238

xxxi. Gearheart \& Weishaln, M.W. (1994). A Comparative Study of Special Education in India and China.

xxxii. Norwich, B. (2002). Education, inclusion and individual differences: Recognising and resolving dilemmas. British Journal of Educational Studies. 50 (4), pp.482-502

xxxiii. Peters, S. (2004). Inclusive Education: An EFA Strategy for all Children. Washington DC: World Bank. 
xxxiv. UNESCO, (2009). Policy guidelines on inclusion in education. Retrieved from unesdoc.unesco.org/ images/ oo17/ 001778/ 177849e.pdf

xxxv. UNESCO, (2009). Towards inclusive education for children with disabilities: A Guideline. UNESCO Bangkok, 2009. (RBE) Mon Luang Pin Malakul. Centenary Building, 920 Sukhumvit. 